\title{
Computational reverse chemical ecology: Virtual screening and predicting behaviorally active semiochemicals for Bactrocera dorsalis
}

\author{
Kamala Jayanthi P D ${ }^{1 \dagger}$, Vivek Kempraj ${ }^{1 *}$, Ravindra M Aurade ${ }^{1}$, Tapas Kumar Roy ${ }^{2}$, Shivashankara K S ${ }^{2}$ \\ and Abraham Verghese ${ }^{1}$
}

\begin{abstract}
Background: Semiochemical is a generic term used for a chemical substance that influences the behaviour of an organism. It is a common term used in the field of chemical ecology to encompass pheromones, allomones, kairomones, attractants and repellents. Insects have mastered the art of using semiochemicals as communication signals and rely on them to find mates, host or habitat. This dependency of insects on semiochemicals has allowed chemical ecologists to develop environment friendly pest management strategies. However, discovering semiochemicals is a laborious process that involves a plethora of behavioural and analytical techniques, making it expansively time consuming. Recently, reverse chemical ecology approach using odorant binding proteins (OBPs) as target for elucidating behaviourally active compounds is gaining eminence. In this scenario, we describe a "computational reverse chemical ecology" approach for rapid screening of potential semiochemicals.
\end{abstract}

Results: We illustrate the high prediction accuracy of our computational method. We screened 25 semiochemicals for their binding potential to a GOBP of B. dorsalis using molecular docking (in silico) and molecular dynamics. Parallely, compounds were subjected to fluorescent quenching assays (Experimental). The correlation between in silico and experimental data were significant $\left(r^{2}=0.9408 ; P<0.0001\right)$. Further, predicted compounds were subjected to behavioral bioassays and were found to be highly attractive to insects.

Conclusions: The present study provides a unique methodology for rapid screening and predicting behaviorally active semiochemicals. This methodology may be developed as a viable approach for prospecting active semiochemicals for pest control, which otherwise is a laborious process.

\section{Background}

Olfaction studies have experienced an upsurge with respect to chemical ecology and neuroethology of insects [1]. This was made possible through the discovery of proteins related to olfaction [2]. Olfaction is achieved through two low-molecular weight $(10-20 \mathrm{kDa})$ proteins, odorant binding proteins (OBPs) and odorant receptors (ORs) [3,4]. OBPs are the first proteins to recognize and bind to odor molecules in the long cascade of olfactory signal transduction [5-7]. OBPs interact with odors that enter through tiny pores present on the insect's antenna

\footnotetext{
* Correspondence: vivek.kempraj@gmail.com

${ }^{\dagger}$ Equal contributors

${ }^{1}$ National Fellow Lab, Division of Entomology and Nematology, Indian

Institute of Horticultural Research, Bangalore, India

Full list of author information is available at the end of the article
}

forming an OBP-Odor complex. The complex transports odor molecules to ORs thereby starting the signal transduction cascade leading to behavioural outputs [8-10]. Although ORs recognize odors even in the absence of OBPs [11], high concentration of OBPs in the sensillar lymph in insects elicit questions of their physiological role. It is suggested that OBPs are involved in olfactory response, concluding that the specificity resides in the OBPs rather than in the odor molecules [12]. This contradicts the results obtained in studies using olfactory receptors expressed in heterologous systems $[13,14]$. It seems logical for OBPs to have a role in insect olfaction, helping insect in perceiving specific odors in this malodorous world where insects forage, mate, oviposit and discriminate between species through specific odor molecules. From earlier studies it has become clear that

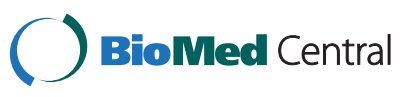

(c) 2014 P D et al.; licensee BioMed Central Ltd. This is an Open Access article distributed under the terms of the Creative Commons Attribution License (http://creativecommons.org/licenses/by/2.0), which permits unrestricted use, distribution, and reproduction in any medium, provided the original work is properly credited. 
OBPs of insects have relevance in olfaction, acting as a liaison between the external environment and behavioural output [15]. Postulating against the specificity of OBPs is their low diversity in species and their broad binding spectrum to molecules of different chemical structures [16,17]. There are strong evidences that OBPs are involved in odorant discrimination, receptor sensitivity and specificity [18-23]. With such fortified evidence on the involvement of OBP in insect olfaction, it is reasonable for OBPs to serve as a molecular target in identifying potential behaviourally active compounds [24-26].

'Reverse chemical ecology' [26,27] is a new concept for screening of attractants based on the binding ability of OBPs to test compounds rather than going through series of behavioural bioassays. This approach involves the study of the binding potential between a characterized OBP (protein) and an odor molecule (ligands) which can be simulated using computers. Here we describe a "computational reverse chemical ecology" approach involving a high performance drug discovery method to predict behaviourally active compounds for $B$. dorsalis. The compounds were also subjected to tryptophan quenching (binding assay) and behavioural assays to prove the efficiency of our approach. Computational methods may accelerate the screening process, thus, limiting our focus to small number of potential compounds that may be used in pest management.

\section{Results}

\section{Odorant-binding protein and 3D model prediction}

SDS-PAGE proved that the OBP was approximately $14 \mathrm{kDa}$ in size and the isolated OBP was pure as evident by a single band in the gel (Figure 1) and demonstrated that the purified protein can be used for further investigation. The purified protein band was subjected to MALDI-TOF-MS and the partial sequence was blasted with submitted OBPs of $B$. dorsalis (Figure 2A). The BLAST results showed $100 \%$ sequence match with a previously isolated and characterized OBP of $B$. dorsalis (GenBank ID: ACB56577.1). Therefore, this previously sequenced protein was used for 3D model prediction. The Profile 3D score of the selected model was 48.34 and exceeded the minimum requirement value of 26.85 . The predicted model consists of $6 \alpha$-helices that are located between 47-65 ( $\alpha 1), 72-85(\alpha 2)$, 96-102 ( $\alpha 3)$, 105-118 $(\alpha 4), 126-140(\alpha 5)$ and 142-146 $(\alpha 6)$. There also existed 3 pair of disulphide bridges that may play a role in stabilizing the structure (Figure 2B).

\section{Molecular docking, prediction and bioassay of behaviorally active compounds}

A 3D structure of the isolated OBP with the highest score was selected and used in docking studies. We used an online molecular docking tool "Docking Server". The

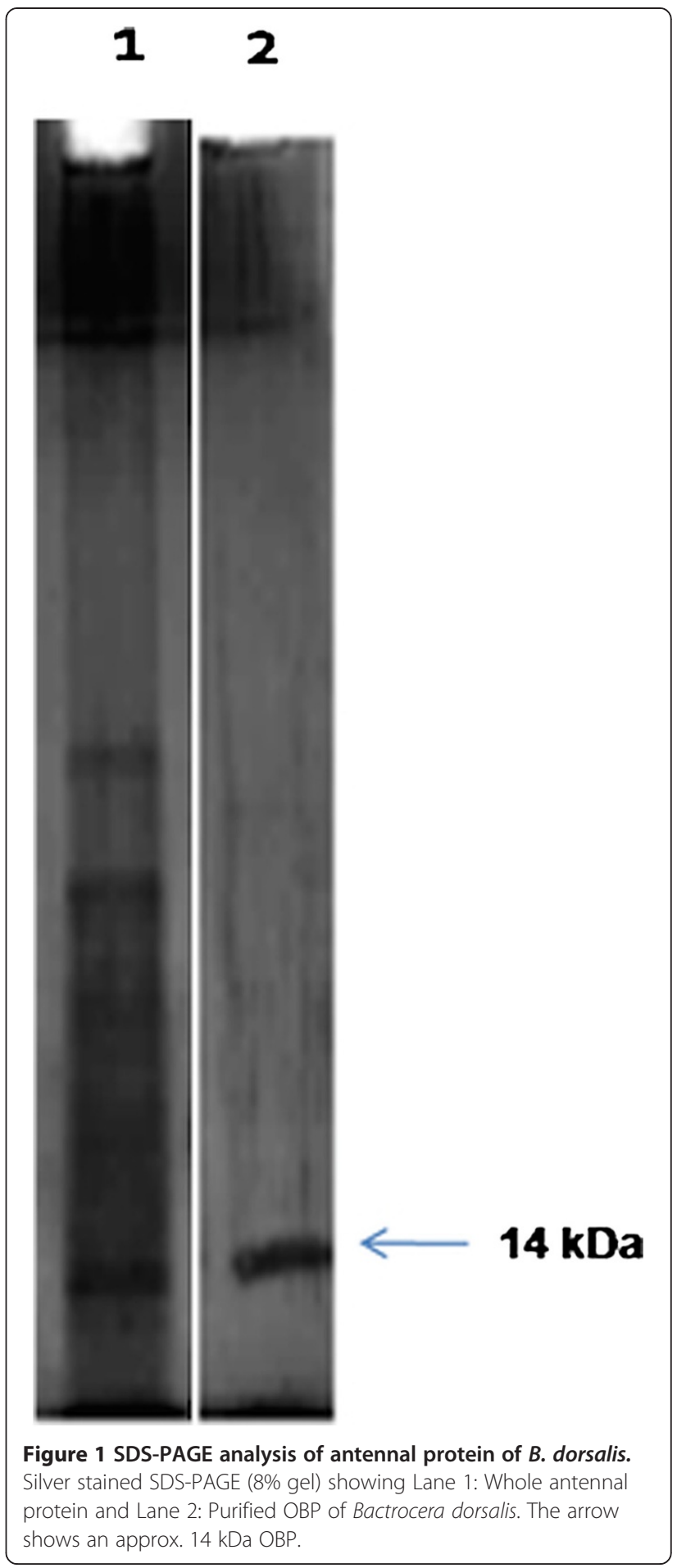

3D structures of protein and selected semiochemicals were loaded to the server. The results were processed and arranged for prediction. Thermodynamically, a ligand binds tightly to the active site of the protein when the free binding energy is low. Therefore, compounds with lower free binding energy were predicted to be behaviourally active. To aid in our prediction process 


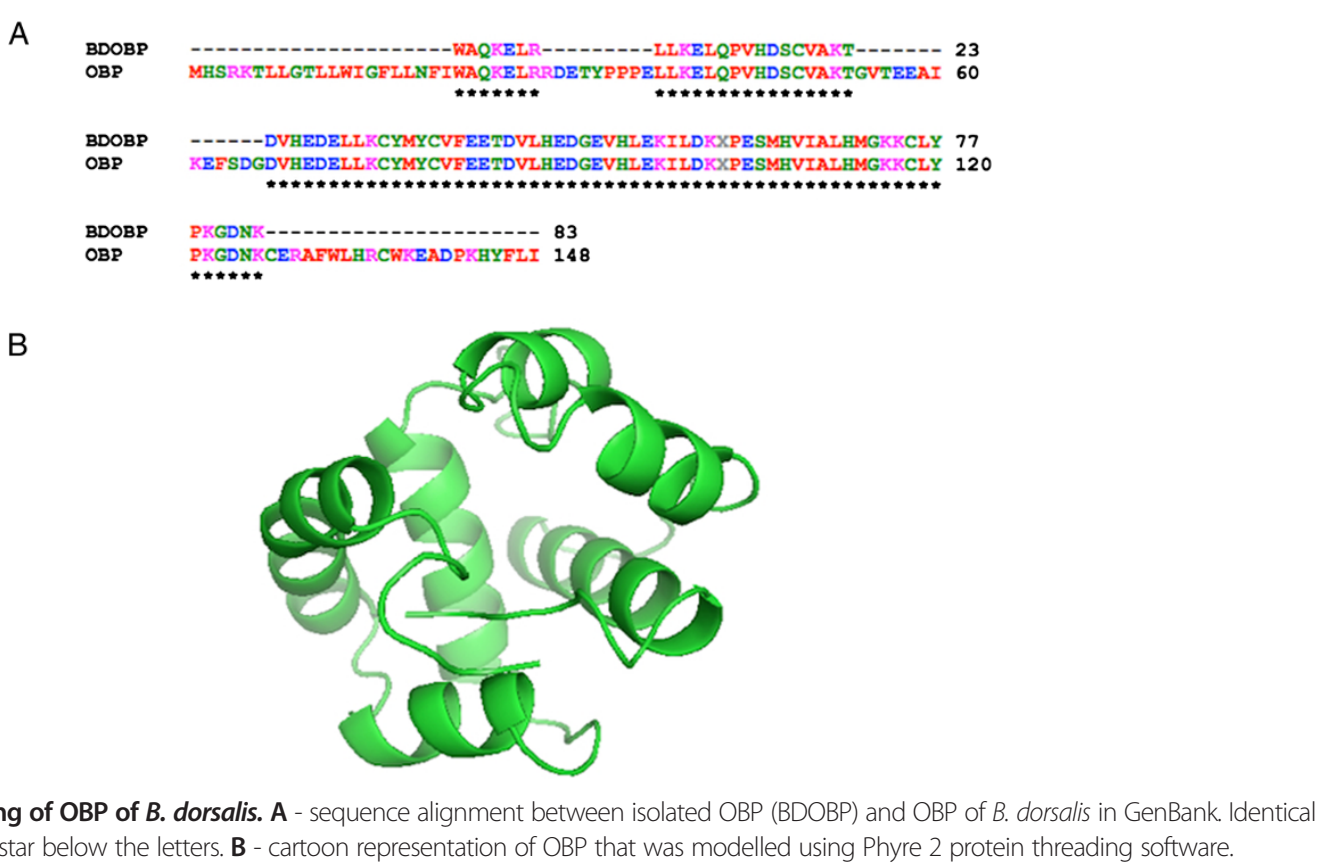

Figure 2 Structural modeling of OBP of $\boldsymbol{B}$. dorsalis. A - sequence alignment between isolated OBP (BDOBP) and OBP of B. dorsalis in GenBank. Identical residues are highlighted with star below the letters. $\mathbf{B}$ - cartoon representation of OBP that was modelled using Phyre 2 protein threading software.

compounds showing free binding energy less than -4.00 were considered behaviourally active and compounds with free binding energy more than -4.00 were used for comparison. First, we conducted a tryptophan quenching assay to find the binding potential of the selected compounds. Second, we conducted a behavioural assay to validate if the predicted compounds were behaviourally active or not. Tryptophan quenching was carried out with the isolated OBP and predicted compounds at concentrations ranging from $0-5000 \mathrm{nM}$. Kd value was estimated by fitting the fluorescence quenching data to an equation describing a single binding site present as a default in Prism Graph Pad version 5.01 for OS X. Percent quenching was determined and the graphs for all test compounds is shown in Additional file 1: Figure S1. The predicted compounds showed high quenching as evident by the Kd values. Kd values ranged from $600-6000$ $\mathrm{nM}$. The Trp fluorescence quenching spectrums of OBP with test compounds are shown in Additional file 2: Figure S2. The results are interesting because the compounds we predicted behaviourally active had tighter binding as evident by quenching and lower $\mathrm{Kd}$ values. Computer simulations or in-vitro binding assay of OBPs may not be an exact measure of the behavioural activity of an insect; however it may be relevant to the functional characterization of an OBP. Therefore, behavioural assays are needed to ascertain the nature (attractant or repellent) of the predicted compounds.

Behavioural assays were conducted to find the activity of predicted compounds. Using the behavioural assay data, a unified estimator, attraction Index (AI) was calculated (see
Method for formula). From the data we found that methyl eugenol that was predicted as highly behaviourally active by its free binding energy showed the highest attraction $74.4 \%$ (Free binding energy $=-5.63 ; \mathrm{AI}=0.50$ ) and the lowest attraction was exhibited by ethanol with $6.67 \%$ (Free binding energy $=-2.43 ; \mathrm{AI}=-0.84$ ) of flies attracted towards them (see Figure 3).

Statistical validation of computational and behavioural assays is crucial in such studies. As $\mathrm{Kd}$ and free binding energy are dependent, considering both for validation of the method is not sensible. Analysis carried out to standardize the dependable scoring functions for estimating the semiochemical efficiency showed significant correlation for both in silico Kd (Pearson $r=-0.7974$; $P<0.0001$ ) and free binding energy (Pearson $r=-0.9728$; $P<0.0001$ ) to AI (Figures 4 and 5). Regression analysis showed that the scoring function 'free binding energy' $\left(F=90.41 ; P<0.001 ; r^{2}=0.9464\right)$ to be the best variable to predict behaviourally active compounds. Therefore, free binding energy was used as a dependable and robust scoring function. Then, correlation between in silico $\mathrm{Kd}$ and Experimental Kd was significantly positive with $r^{2}=0.9408$ $(P<0.0001)$ and demonstrated that in silico data could be used for further studies (Figure 6).

\section{Discussion}

Constant co-evolution between phytophagous insects and their host plants suggests that insects use chemical cues of their hosts to locate them. The tephritid fruit fly, $B$. dorsalis, uses a range of commercial fruit crops as hosts and cause huge losses to farmers in tropical and 


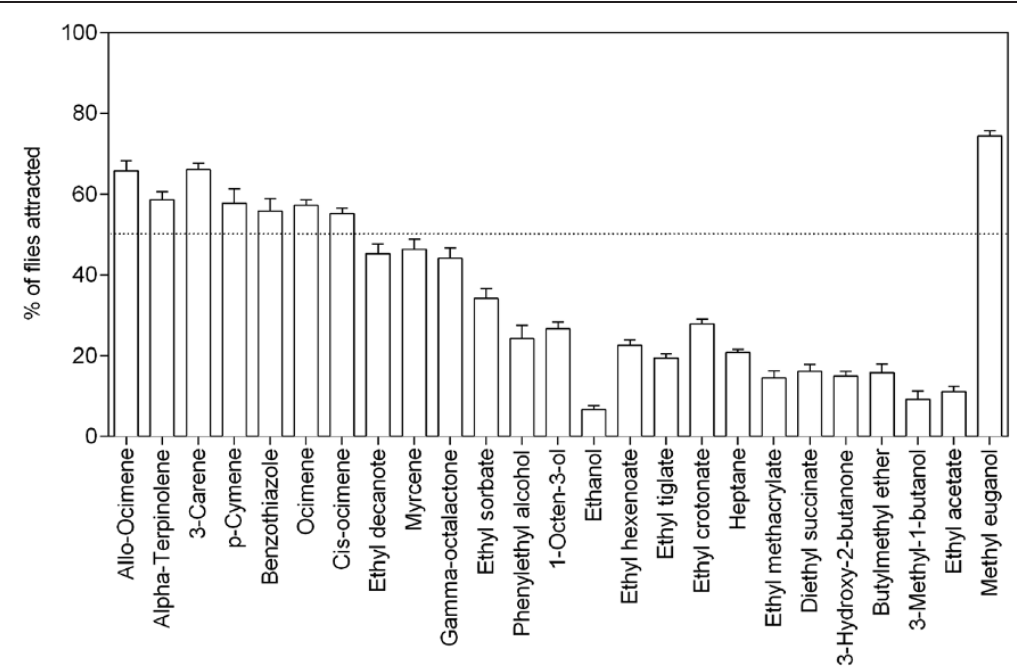

Figure 3 Attraction efficiency of $\mathbf{2 5}$ kairomone compounds to $\boldsymbol{B}$. dorsalis. The test zone contained cellulose disc with 10 uL of individual kairomone and the control zone contained hexane. The mean number of insects in traps (respondents) and insects outside the trap (non-respondents) was used to determine a unified estimator, attraction index (Al). The \% attraction was the mean of 9 individual experiments.

sub-tropical countries. The management option for this pest is mainly concentrated on males, thereby ignoring females that are otherwise highly the main cause of damage. Identifying potential attractants will definitely help us in narrowing down our focus on few potential compounds that may be attractive to females.

Recently, OBPs have shown to be required for the functioning of the olfactory system of insects [28-30] and has been used as a target protein in discovering attractants $[26,27]$. General odorant binding proteins (GOBPs) have a rather broad ligand-binding ability, in contrast to specificity. Therefore, using a consecutively produced general OBP as a target protein to a plethora of host volatiles may help us discover behaviourally active compounds. Although our method seems intriguing, it could not distinguish between repellents or attractants. Therefore, the method has been concluded with behavioural assays to verify the nature of

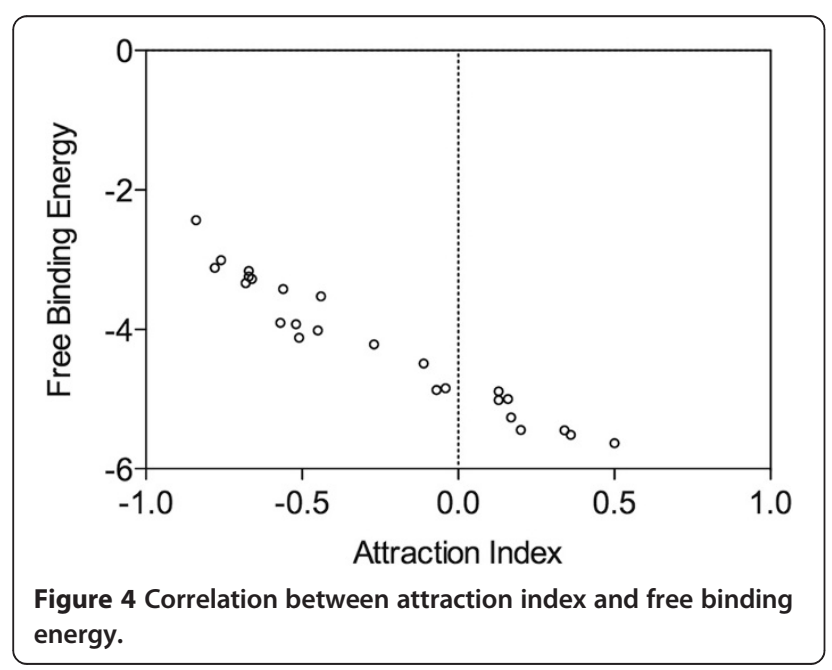

the predicted compounds. Our method is a simple in silico approach for predicting and narrowing down to a set of behaviourally active compounds thereby reducing research cost and time.

\section{Conclusions}

The results of the present study shows that our methodology used in this study is able to predict behaviourally active compounds accurately. Our unique approach helps us screen large number of compounds and predict their efficacy. It may be developed as a viable approach in discovering behaviourally active semiochemicals for integrated pest management strategies that otherwise is laborious and a costly affair. We anticipate that further improvements in the area of computational biology and proteomics may increase the efficiency of our method and short comes. Further the predicted compounds are to be validated in the field in case they are to be used for pest control.

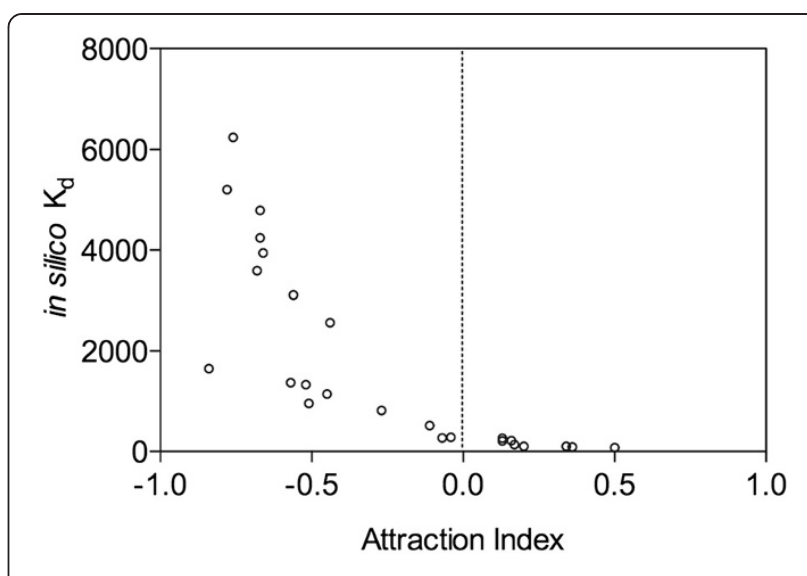

Figure 5 Correlation between attraction index and in silico $\mathrm{K}_{\mathrm{d}}$. 


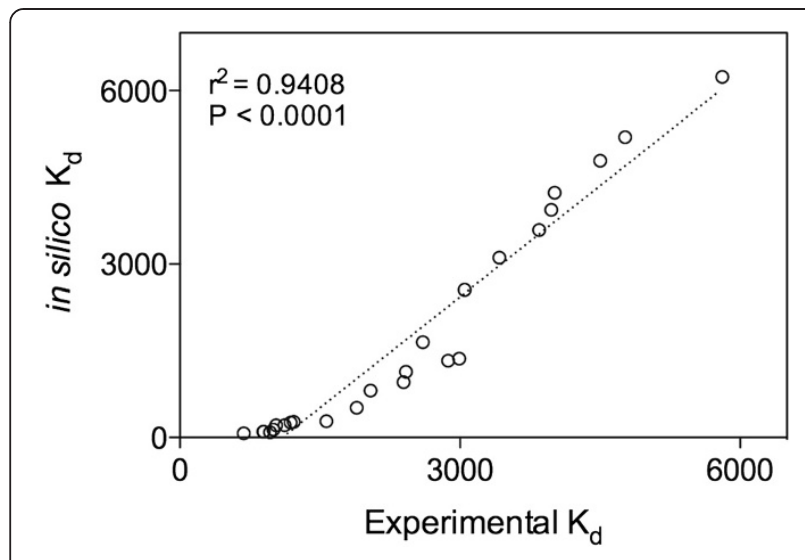

Figure 6 Correlation between experimental $K_{d}$ and in silico $K_{d}$.

\section{Methods}

\section{Chemicals}

All semiochemicals used were 99\% pure and were purchased from Sigma-Aldrich, USA. Other chemicals were of analytical grade.

\section{Insects}

The mango fruit fly, $B$. dorsalis, was reared on banana in the laboratory [31]. Fruits were exposed for $24 \mathrm{~h}$ to fruit fly cultures for oviposition. The oviposited fruits were kept in a plastic box containing fine sterilized sand. The sand was sieved after 10 days to aid in collection of pupa. The pupae were kept in cages for adults to emerge and were maintained at optimum conditions of $27 \pm 2^{\circ} \mathrm{C}, 75 \%$ $\mathrm{RH}$ and 12:12 h dark light cycle. The emerged adults were fed with $10 \%$ honey solution and yeast extract ad labium. Antennae from gravid females (15 days old) were excised after emergence and stored at $-20^{\circ} \mathrm{C}$ until use.

\section{Extraction, purification and characterization of OBP}

A consecutively produced OBP was selected for the study and was extracted from the antenna of gravid, 15 -day-old female $B$. dorsalis. Antennas collected were homogenized in cold $50 \mathrm{mM}$ Tris- $\mathrm{HCl}$ buffer, $\mathrm{pH}$ 7.4. The homogenate was centrifuged at $10,000 \mathrm{rpm}$ for $10 \mathrm{~min}$ at $4^{\circ} \mathrm{C}$. The protein concentration was confirmed using Bradford method [32]. OBP was precipitated using $60 \%$ ammonium sulphate and dialyzed against $50 \mathrm{mM}$ Tris- $\mathrm{HCl}$ buffer, $\mathrm{pH}$ 7.4. Most of the OBPs are in the range of $10-15 \mathrm{kDa}$, therefore, we used a $15-\mathrm{kDa}$ cut off membrane to purify our protein. Further, a single band with molecular weight of approximately $14 \mathrm{kDa}$ was purified by preparative SDS-PAGE. The corresponding band was electro-eluted for further analysis. The protein purity was analyzed by SDSPAGE [33]. The band containing purified protein was cut and digested with trypsin under sterile condition and submitted to the Molecular Biophysics Unit, IISc,
Bangalore for De-novo sequencing of the OBP using MALDI-TOF/LC-MS. The MALDI-MS spectra were searched for entries among the database. The partial sequence was compared with those of the proteins from MASCOT or BLAST similarity search to obtain homology.

\section{Selection of compounds for docking studies}

Twenty-five volatile compounds that are identified in the headspace volatiles of the favoured host (Mango cv. Alphonso and Chausa) of $B$. dorsalis were selected for our study.

\section{Sequence retrieval and 3D modeling of OBP}

During our homology search an antenna OBP of Bactrocera dorsalis with homology to our isolated protein existed in the protein sequence database (GenBank ID: ACB56577.1) of the National Centre for Biotechnology Information. A thorough search for the three dimensional structure of the OBP in PDB (Protein Database: http://www.rcsb.org/pdb) ascertained the non-existence of $3 \mathrm{D}$ structure of this protein. Therefore, the complete OBP submitted in GenBank was used for construction of a 3D model for our in-silico docking studies. Three-dimensional modelling of the antennal OBP of $B$. dorsalis was developed using an online protein threading (PHYRE 2) and homology modelling (SWISS-MODEL) online programs. AgamOBP1, a female odorant binding protein from Anopheles gambiae (PDB code: 2ERB) [34], CquiOBP1, a female-dominant odorant binding protein from Culex quinquefasciatus (PDB code: 3OGN) [35,36] and AaegOBP1, a major female- enriched odorant-binding protein from Aedes aegypti (PDB code: 3K1E) [6] were suggested as templates by the program. Multiple sequence alignment of the OBPs was carried out using Clustal O (see Additional file 3). It was found that the proteins had a identity of $48.993 \%$. Identical and similar positions were 73 and 36 respectively. Based on the identified structural templates and the corresponding sequences, several 3D models were constructed using Modeler module in Discovery Studio 2.0 (Accelrys Software Inc., USA). The unaligned residues were deleted and the proteins were refined. The profiles-3D method was used as a standard in evaluating the fitness between the sequences and the $3 \mathrm{D}$ models. The model with the highest score of profile-3D was optimized and considered for further processing. Multiple sequence alignment (MSA) of the protein sequence used in the study is provided (see Additional file 3).

\section{Molecular docking and molecular dynamics simulations}

Molecular docking was carried out using "Docking server" [37]. All compounds that were proved attractive to B. dorsalis from previous studies were considered for docking studies. Three-dimensional structures of compounds were from NCBI. Scoring function, free energy 
of binding was considered in tagging the compounds active. Docking was carried out 10 times with the selected OBP and the ligands (semiochemicals). For each run, the 10 highest scoring docking poses were saved and were further processed for molecular dynamics simulations and the free binding energies were calculated as previously described [38]. Briefly, all simulations were performed using AMBER 8.0 to suit our system. The ff03 force field was used and the time step was set at $0.5 \mathrm{fs}$. The temperature was set and maintained to a constant $300 \mathrm{~K}$ or $27^{\circ} \mathrm{C}$ and MD simulations were preformed for 700 ps for equilibration. The MD simulation calculations and the estimation of free binding energies by the MMPB/SA method were preformed simultaneously. We did not use the MDGRAPE-3 system [38] for our simulations; therefore the average time was around $16-18 \mathrm{~h}$ per simulation. However, using faster systems may help us speedup the process. For calculation of free binding energy, the production MD trajectory was recorded for the last period of $610 \mathrm{ps}$. This was done as our protein was modelled and may contain errors. The MM-PB/SA was employed for calculating the free energy of binding and the equation described by Okimoto et al [37] was used. Each free binding energy of a protein-ligand complex is the minimum energies from among the energies of multiple poses (atleast 10 poses). All docking and MD simulations were done at $\mathrm{pH} 7$.

\section{Measurement of ligand-OBP binding affinity by tryptophan fluorescence quenching}

Tryptophan (Trp) fluorescence quenching assay was carried using Varian Cary Eclipse Spectroflurometer as described previously [34]. Briefly, OBP $(10 \mathrm{ug} / \mathrm{ml})$ was titrated in $50 \mathrm{mM}$ Tris- $\mathrm{HCl}$ buffer, $\mathrm{pH} 7.4$ with increasing concentration of ligands, while quenching of Trp fluorescence was monitored at $307 \mathrm{~nm}$ following excitation at $280 \mathrm{~nm}$. Slit width for excitation and emission was 5 and $10 \mathrm{~nm}$, respectively. $\mathrm{Kd}$ and $\Delta \mathrm{F} \max$ values were noted following fitting of data to an equation describing binding to a single affinity site. Quenching percent (\% Q) was calculated using the formula, $\% \mathrm{Q}=(\Delta \mathrm{F} / \mathrm{F} 0 \times 100)$ in relation to the initial value after addition of ligand at a given concentration $[\mathrm{S}]$. F0 and $\Delta \mathrm{F}$ were initial fluorescence intensity and fluorescence intensity after addition of ligand, respectively.

\section{Behavioural assay}

Forty $B$. dorsalis gravid females were released into an assay cage measuring $30 \times 30 \times 30 \mathrm{~cm}$ and were allowed to acclimatize. A test zone was determined and outlined with a cellulose disc ( $5 \mathrm{~cm}$ diameter) in a small plastic fly trap. Semiochemical stocks of predicted attractants and non-attractants were prepared by dissolving a specific amount of the compounds in redistilled hexane to give a final concentration of $0.05 \mathrm{ppm}$. A known amount $(10 \mathrm{uL})$ of the semiochemical was dispensed on to the test zone. The traps were allowed for the solvent to evaporate and placed in assay cages. The number of insects trapped in the test zone was counted after $24 \mathrm{~h}$. The experiment was repeated 9 times. The mean number of insects in traps (respondents) and insects outside the trap (non-respondents) was used to determine a unified estimator, attraction index (AI), that was calculated using the formula: $\mathrm{AI}=($ \# mean respondents - \# mean non - respondents)/(\# mean respondents + \# mean non respondents), where the \# mean respondents indicates the mean number of insects in the trap and \# mean nonrespondents indicates the number of insects that did not respond. All data related to in silico and in vitro studies are provided in Additional files 4 and 5.

\section{Additional files}

Additional file 1: Fluorescence quenching curves of 25 ligands to OBP of $\boldsymbol{B}$. dorsalis. Percent quenching of tryptophan is shown in the graphs.

Additional file 2: Fluorescence quenching spectrum of $\mathbf{2 5}$ ligands to OBP of $B$. dorsalis. OBP was titrated with increasing concentration of test compounds. The upper first peak (red) is the spectrum of OBP alone. The following spectrum or lines corresponds to the increasing concentrations of the individual test compounds titrated. The Trp

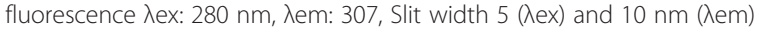
at $24^{\circ} \mathrm{C}$. Data are means of three independent experiments.

Additional file 3: Multiple sequence alignment of OBPs in this study. Additional file 4: In silico analysis of 25 semiochemicals docked with OBP and the outputs by the "Docking Server".

Additional file 5: Consolidated data of behavioural, in vitro and in silico experiments.

\section{Competing interests}

The authors declare that they have no competing interests.

\section{Authors' contributions}

KJPD and VK designed the work, VK and RMA conducted behavioural, in vitro and in silico experiments, VK and KJPD drafted the manuscript and contributed equally to the study, TKR, SKS and AV provided instrumentations required for the study. All authors have approved the final version of the manuscript.

\section{Acknowledgements}

We thank Rajanna TS and Nagarathna M for maintaining insect cultures. KJPD thanks ICAR for funding the work through the National Fellow Project. This work was supported by the Indian Council for Agricultural Research (ICAR), India. The funders have no role in study design, data collection and analysis, decision to publish or preparation of the manuscript.

\section{Author details}

${ }^{1}$ National Fellow Lab, Division of Entomology and Nematology, Indian Institute of Horticultural Research, Bangalore, India. ${ }^{2}$ Division of Plant Physiology and Biochemistry, Indian Institute of Horticultural Research, Bangalore, India.

Received: 19 August 2013 Accepted: 3 March 2014

Published: 19 March 2014

\section{References}

1. Araneda $\mathrm{RC}$, Kini $A D$, Firestein $\mathrm{S}$ : The molecular receptive range of an odorant receptor. Nat Neurosci 2000, 3:1248-1255. 
2. Ronnett GV, Moon C: G proteins and olfactory signal transduction. Annu Rev Physiology 2002, 64:189-222. 12

3. Sun YF, De Biasio F, Qiao HL, lovinella I, Yang SX, Ling Y, Riviello L, Battaglia D, Falabella P, Yang XL, Pelosi P: Two odorant- binding proteins mediate the behavioural response of aphids to the alarm pheromone (E)- $B$-Farnesene and structural analogues. PLOS ONE 2012, 7(3):e32759. doi: 10.1371/journal. pone.0032759.

4. Pophof B: Moth pheromone binding proteins contribute to the excitation of olfactory receptor cells. Naturwissenschaften 2002, 89:515-518.

5. Yin J, Feng H, Sun H, Xi J, Cao Y, Li K: Functional analysis of general odorant binding protein 2 from the meadow moth, Loxostege sticticalis L. (Lepidoptera: Pyralidae). PLoS ONE 2012, 7(3):e33589. doi:10.1371/journal. pone.0033589

6. Leite NR, Krogh $R, X u$ W, Ishida Y, lulek J, Leal WS, Oliva G: Structure of an odorant- binding protein from the mosquito Aedes aegypti suggests a binding pocket covered by a pH-sensitive "Lid". PLOS ONE 2009, 4(11):e8006. doi: 10.1371/journal.pone.0008006

7. Jiang QY, Wang WX, Zhang Z, Zhang L: Binding specificity of locust odorant binding protein and its key binding site for initial recognition of alcohols. Insect Biochem Mol Biol 2009, 39:440-447.

8. Vogt RG, Callahan FE, Rogers ME, Dickens JC: Odorant binding protein diversity and distribution among the insect orders, as indicated by LAP, an OBP-related protein of the true bug Lygus lineolaris (Hemiptera, Heteroptera). Chem Senses 1999, 24:481-495.

9. Pelosi $P$, Maida R: Odorant-binding proteins in insects. Comp Biochem Physiol 1995, 111:503-514.

10. Steinbrecht RA: Odorant-binding proteins: expression and function. Ann N Y Acad Sci 1998, 855:323-332. 13

11. Giorgi D, Rouquier S, Gaillard I: Olfactory receptors. Cell Mol Life Sci 2004, 61:456-469.

12. Horst R, Damberger F, Luginbuhl P, Guntert P, Peng G, Nikonova L, Leal WS, Wuthrich K: NMR structure reveals intra-molecular regulation mechanism for pheromone binding and release. PNAS 2001, 98:14374-14379.

13. Wetzel $\mathrm{CH}$, Behrendt HJ, Gisselmann G, Stortkuhl KF, Hovemann B, Hatt H: Functional expression and characterization of a Drosophila odorant receptor in a heterologous cell system. PNAS 2001, 98:9377-9380.

14. Reisert J, Restrepo D: Molecular tuning of odorant receptors and its implication for odor signal processing. Chem Senses 2009, 34:535-545.

15. Vogt RG: Molecular basis of pheromone detection in insects. In Comprehensive Insect Physiology, Biochemistry, Pharmacology and Molecular Biology. Edited by Gilbert LI, latro K, Gill S. London: Elsevier; 2005:753-804.

16. Pelosi P: Perireceptor events in olfaction. J Neurobiol 1996, 30:3-19.

17. Pelosi P: The role of perireceptor events in vertrbrate olfaction. Cell Mol Life Sci 2001, 58:503-509.

18. Loebel D, Marchese S, Krieger J, Pelosi P, Breer H: Sub-type of odorant-binding proteins: heterologous expression and ligand binding. Eur J Biochem 1998, 254:318-324.

19. Brian L, Nespoulous C, Perez V, Remy JJ, Huet JC, Pernollet JC: Ligand-binding properties and structural characterization of a novel rat odorant-binding protein variant. Eur J Biochem 2000, 267:3079-3089.

20. Tcatchoff L, Nespoulous C, Pernollet JC, Briand L: A single lysyl residue defines the binding specificity of human odorant-binding protein for aldehydes. FEBS Lett 2006, 580:2102-2108.

21. Vidic J, Grosclaude J, Monnerie R, Persuy MA, Badonnel K, Baly C, Caillol M, Briand L, Salesse R, Pajot-Augy E: On a chip demonstration of a functional role for odorant binding protein in the preservation of olfactory receptor activity at high odorant concentration. Lab Chip 2008, 8:678-688.

22. Ko HJ, Park TH: Enhancement of odorant detection sensitivity by the expression of odorant-binding protein. Biosens Bioelectron 2008, 23:1017-1023

23. Ko HJ, Lee SH, Oh EH, Park TH: Specificity of odorant-binding proteins: a factor influencing the sensitivity of olfactory receptor-based biosensors. Bioprocess Biosyst Eng 2010, 33:55-62.

24. Gotzek D, Robertson HM, Wurm Y, Shoemaker D: Odorant binding proteins of the red imported fire ant, Solenopsis invicta: an example of the problems facing the analysis of widely divergent proteins. PLOS ONE 2011, 6(1):e16289. doi:10.1371/journal.pone.0016289.

25. Vandermoten S, Francis F, Haubruge E, Leal WS: Conserved odorant-binding proteins from aphids and eaves dropping predators. PLOS ONE 2011, 6(8):e23608. doi: 10.1371/journal.pone.0023608.
26. Leal WS, Barbosa RMR, Xu W, Ishida Y, Syed Z, Latte N, Chen AM, Morgan TI, Cornel AJ, Furtado A: Reverse and conventional chemical ecology approaches for the development of oviposition attractants for Culex mosquitoes. PLOS ONE 2008, 3(8):e3045. doi:10.1371/journal.ponr.0003045.

27. Leal WS: Pheromone reception. Topics in Curr Chem 2005, 240:1-36.

28. Xu PX, Atkinson R, Jones DNM, Smith DP: Drosophila OBP LUSH is required for activity of pheromone-sensitive neurons. Neuron 2005, 45:193-200.

29. Matsuo T, Sugaya S, Yasukawa J, Aigaki T, Fuyama Y: Odorant-binding proteins OBP57d and OBP57e affect taste perception and host-plant preference in Drosophila sechellia. PLoS Biol 2007, 5:985-996.

30. Biessmann $H$, Andronopoulou E, Biessmann MR, Douris V, Dimitratos SD, Eliopoulos E, Guerin PM, Latrou K, Justice RW, Krober T, Marinotti O, Tsitoura P, Woods DF, Walter MF: The Anopheles gambiae odorant binding protein 1 (AgamOBP1) mediates indole recognition in the antennae of female mosquitoes. PLOS ONE 2010, 5(3):e9471. doi:10.1371/journal.pone.0009471.

31. Kamala Jayanthi PD, Verghese A: A simple and cost-effective mass rearing technique for the tephritid fruit fly, Bactrocera dorsalis (Hendel). Curr Sci 2001, 82:266-268.

32. Bradford MM: Rapid and sensitive method for the quantitation of microgram quantities of protein utilizing the principle of protein-dye binding. Anal Biochem 1976, 72:248-254.

33. Laemmli UK: Cleavage of structural proteins during the assembly of the head of bacteriophage T4. Nature 1970, 227:680-685.

34. Gong Y, Tang H, Bohne C, Plettner E: Binding conformation and kinetics of two Pheromone-binding proteins from the gypsy moth Lymantria dispar with biological and non-biological ligands. Biochemistry 2010, 49:793-801.

35. Wogulis M, Morgan T, Ishida Y, Leal WS, Wilson DK: The crystal structure of an odorant binding protein form Anopheles gambiae: evidence for a common ligand release mechanism. Biochem Biophys Res Commun 2006, 339:157-164.

36. Mao Y, Xu X, Xu W, Ishida Y, Leal WS, Ames JB, Clardy J: Crystal and solution structures of an odorant-binding protein from the southern house mosquito complexed with an oviposition pheromone. PNAS 2010, 107:19102-19107.

37. Bikadi Z, Hazai E: Application of the PM6 semi-empirical method to modeling proteins enhances docking accuracy of AutoDock. J Cheminfor 2009, 1:15

38. Okimoto N, Futatsugi N, Fuji H, Suenaga A, Morimoto G, Yanai R, Ohno Y, Narumi T, Yaiji M: High- performance drug discovery: computational screening by combining docking and molecular dynamics simulations. PLoS Comput Biol 2009, 5(10):e1000528. doi:10.1371/journal.pcbi.1000528.

doi:10.1186/1471-2164-15-209

Cite this article as: P D et al:: Computational reverse chemical ecology: Virtual screening and predicting behaviorally active semiochemicals for Bactrocera dorsalis. BMC Genomics 2014 15:209.

\section{Submit your next manuscript to BioMed Central and take full advantage of:}

- Convenient online submission

- Thorough peer review

- No space constraints or color figure charges

- Immediate publication on acceptance

- Inclusion in PubMed, CAS, Scopus and Google Scholar

- Research which is freely available for redistribution 